\title{
Effects of Permeability Coefficient on Land Reclamation in Coal Mining Areas in Chongqing
}

\author{
Lin Liu \\ College of Resources and Environment \\ Southwest University, SWU \\ Chongqing, China \\ liulinswu@163.com \\ Jianwei Yun \\ College of Resources and Environment \\ Southwest University, SWU \\ Chongqing, China \\ 371284646@qq.com \\ Weihua Zhang * \\ College of Resources and Environment \\ Southwest University, SWU \\ Chongqing, China \\ swuwater@126.com \\ * Corresponding Author
}

\author{
Jianrong Li \\ Fengdu Water Resources Bureau \\ Chongqing, China \\ 843642063@qq.com
}

Kai Luo

College of Resources and Environment

Southwest University, SWU

Chongqing, China

877030885@qq.com

\begin{abstract}
The permeability coefficient decides the land water retention ability to some extent. This study measured soil permeability coefficient in land of coal mining areas with double ring method, in order to show the soil water retention ability and analyzed the relationship between soil infiltration curve and land water retention ability. The results show that soil infiltration curve is affected by the soil texture and soil moisture. If the soil moisture is adequate, the initial permeability curve of soil is steep, oppositely, if the soil moisture content is deficit, the initial permeability curve of soil is flat; for the different soil texture, the stable infiltration rate is largely different, meanwhile, permeability coefficient of sand is larger than that of silt, and the silt is greater than the clay.
\end{abstract}

Keywords-permeability coefficient; land reclamation; double ring method; water retention

\section{INTRODUCTION}

\section{A. The Meaning of Study}

As a typical coal resources city in Southwest region, Chongqing has made important contribution to the local economy after a long period of exploitation of coal resources. But after that there will be formed the mined-out areas in the underground (Zhang Lili, 2014). Therefore, a large areas of subsidence in the earth's surface will cause many problems such as the surface cracking, water dry up and quality of land seriously decline (Hu Chenglin, 2011; Chen Zhantu, 2010). Consequently, it is necessary to discuss land reclamation in the areas.

Land reclamation needs to adjust measures by local conditions (Li Meng, 2012). The survey of topography in
Chongqing indicates: To reclaim the paddy field, the main work is to find the reason of lacking water in paddy. The nature of paddy soil itself is the important factor influencing the paddy field water. Paddy field soil water penetration test can also reveal the permeability of unsaturated soil water change after drought, which reflects the damaged water retention effect of paddy soil itself.

Soil water is one of the key words of farmland soil research. As an important parameter of soil water, permeability coefficient will have influence on land reclamation.

\section{B. Introduction of Infiltration}

Infiltration is the process of water seep into soil at the earth's surface. The physical process of water which pushed by molecular force, capillary force, and the gravity in the soil is an important part in run off.

Runoff and its field determine the infiltration directly (Li Jianzhu, 2008). The infiltration affects the growth of soil water and water going underground, thus, affecting the formation of surface and underground runoff and the size.

Across to water stress condition and operation characteristics, the infiltration process is divided into three parts: 1) Wetting phase. The water is mainly affected by molecular force, adsorbed on the soil particles, forming a thin film of water. 2) Leakage phase. Infiltration water forced by the capillary and gravity move among the soil particles, gradually fill the space of the particles. 3) Penetration phase. The soil is filled with water, the water will move under the gravity till the soil moisture is saturated, which is said saturated flow.

Infiltration can be described by infiltration rate and infiltration capacity. Infiltration rate, also known as 
infiltration intensity, is the amount of seepage water in per unit area and per unit time; Infiltration capacity refers to the maximum infiltration rate under the condition of sufficient water supply in a certain soil type.

The influencing factors of infiltration are the physical properties of soil, rainfall characteristics, basin landform, vegetation and human activities, et al. .

Infiltration rate can be determined directly by field experiments or hydrological analysis (Appels W.M. and Bogaart P.W., 2011).

\section{METHOD AND PRINCIPLE}

\section{A. Experimental Methord}

By far, the most commonly methods are trial pit method, single and double ring method. the trial pit method or single ring method can be used for sand and powder soil, while double ring method is usually adopted for cohesive soil. The soil in experimental area is mainly clay, so the double ring method always are used to test permeability coefficient in unsaturated loose rock zone.

\section{B. Experimental Principle}

Within certain hydrogeological boundary, water is injected to the surface of loose rock strata until the infiltration of water tends to be stable, in other word, the water quantity of infiltration per unit time is approximately equal. Then, Darcy's law is used to calculate permeability coefficient value.

Test site should be selected where the depth of unconfined aquifer is more than $5 \mathrm{~m}$, because, when ground water depth is less than $2 \mathrm{~m}$ the seepage path is too short to measured permeability coefficient accurately.

After excavating a circle pit in test site, two rings are embedded in the bottom. The diameter of outer and inner ring is $50 \mathrm{~cm}$ and $25 \mathrm{~cm}$ respectively, and the height of ring is $50 \mathrm{~cm}$. When testing the two rings should be injected water at the same time and keep the same water height which both outer and inner rings is $10 \mathrm{~cm}$, see Fig .1, the diameter of two water supply barrels are both $0.30 \mathrm{~m}$. Due to the outer ring's restriction, the inner ring can only infiltrate vertically so the text ruled out the error of lateral seepage (Ye Yuntao, Wu Jingwei and Wang Xingkui, 2007). Hence, the way's accuracy is higher than the trial pit method and single loop method.

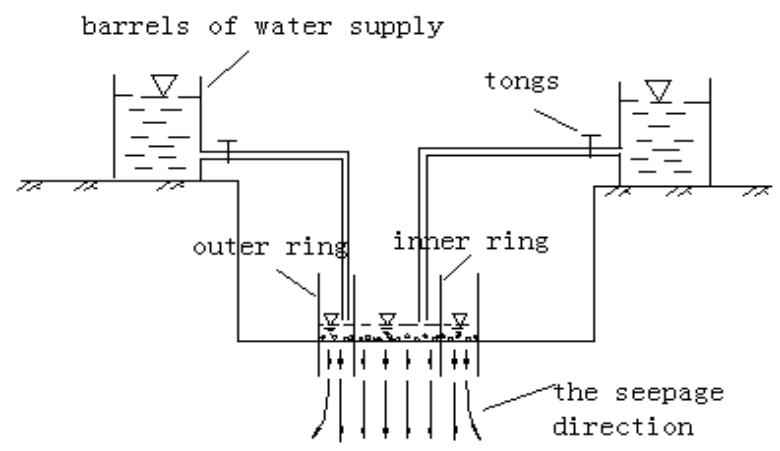

Figure 1. Water penetration test profile sketch.

Water is injected to the inner and the outer ring at the same time and keeps the water at the same height. When infiltration rate is stable, Darcy's law is used to calculate the permeability coefficient here.

The equation of Darcy's law:

$$
\begin{aligned}
& I=\frac{H_{k}+Z+L}{L} \\
& K=\frac{Q}{I \omega}
\end{aligned}
$$

Where: $Q$ is stable seepage flow $\left(\mathrm{m}^{3} / \mathrm{d}\right) ; K$ is permeability coefficient $(\mathrm{m} / \mathrm{s}) ; \omega$ is cross section area of inner ring $\left(\mathrm{m}^{2}\right) ; Z$ is water layer thickness in the crevices (m); $L$ is the depth of water infiltrating from the trial pits to the soil in the trial period $(\mathrm{m}) ; H_{K}$ is capillary pressure which is produced by the process of infiltration in the dry soil, shown by high water (m); $L$ value can be sample with a hand drill to determinate its moisture content changes after the test (Li Yuqin and Zhao Jingbo, 2005); $H_{K}$ defined by Tab. 1. If the test layer is the coarse sand or coarse sand pebble layer, and water layer thickness of trail pit is $10 \mathrm{~cm}, H_{K}$ is very small compared to $Z$ and $L$, therefore, $I$ approximately equal to 1 , then:

$$
K=\frac{Q}{\omega}=v
$$

Where: $v$ is percolation rate. If the test soil is cohesive, calculating $i$ according to plug the actual values of $H_{k}$ in formula $K=v / i$.

TABLE I. DIFFERENT ROCK PROPERTIES ` $\mathrm{H}_{\mathrm{K}}$

\begin{tabular}{llll}
\hline \multicolumn{1}{c}{ Rock's name } & $\mathbf{H}_{\mathbf{k}}(\mathbf{m})$ & \multicolumn{1}{c}{ Rock's name } & $\mathbf{H}_{\mathbf{k}}(\mathbf{m})$ \\
\hline Heavy loam & 1 & Fine-grained clay sand & 0.3 \\
Light loam & 0.8 & Silt & 0.2 \\
Heavy sand loam & 0.6 & Fine sand & 0.1 \\
Light sand loam & 0.4 & Medium san & 0.05 \\
\hline
\end{tabular}

\section{RESULTS ANALYSIS}

\section{A. Description of Study Area}

Qijiang town is located in the north of Chongqing, covering an area of $2178.5 \mathrm{~km}^{2}$. Mountain and hilly accounted for $67.6 \%$ and $32.4 \%$ of the total area respectively. Meteorological terrain is getting lower from south to north and the average elevation is $920 \mathrm{~m}$. Qijiang has many branches, such as Pu river, Qingxi river et al., forming a water network system. Qijiang is situated in the crossroads between Chongqing and Guizhou province, also because of closing to Chongqing, there is a "the South Gate of Chongqing" said.

This paper finds six coal areas in Qijiang town to experiment with double ring method, and their terrains distribution are shown in Tab. 2. 
TABLE II. DIFFERENCE TERRAINS OF THE VILLAGE

\begin{tabular}{lllll}
\hline & $\begin{array}{c}\text { Colliery's } \\
\text { name }\end{array}$ & $\begin{array}{c}\text { County's } \\
\text { name }\end{array}$ & Terrian & $\begin{array}{c}\text { Soil } \\
\text { texture }\end{array}$ \\
\hline site 1 & Shihao & Shihao & Brae & Sand, Silt \\
site 2 & Songzao & Ganshui & Ravine & Clay, Silt \\
site 3 & Datong & Datong & Brae & Silt, Sand \\
site 4 & Fengchun & Shihao & Ravine & Silt \\
site 5 & Yuyang & Anwen & Brae & Silt, Clay \\
site 6 & Tonghua & Anwen & Brae & Silt, Sand \\
\hline
\end{tabular}

B. Experiment Results

According to the experimental data, the formula below can be used to calculate the infiltration rate.

$$
\mathrm{v}=\frac{\mathrm{h} \times \omega_{1}}{T \times \omega_{2}}
$$

Where: $v$ is infiltration rate $(\mathrm{cm} / \mathrm{min}) ; h$ is drop depth of water supply bottle for inner ring $(\mathrm{cm}) ; \omega_{1}$ is cross section area of water supply bottle for inner ring $\left(\mathrm{m}^{2}\right)$; $\mathrm{T}$ is corresponding time $(\mathrm{min}) ; \omega^{2}$ is cross section area of inner $\operatorname{ring}\left(\mathrm{m}^{2}\right)$.

Here, $v$ - $t$ curves of each experimental site are as follows:

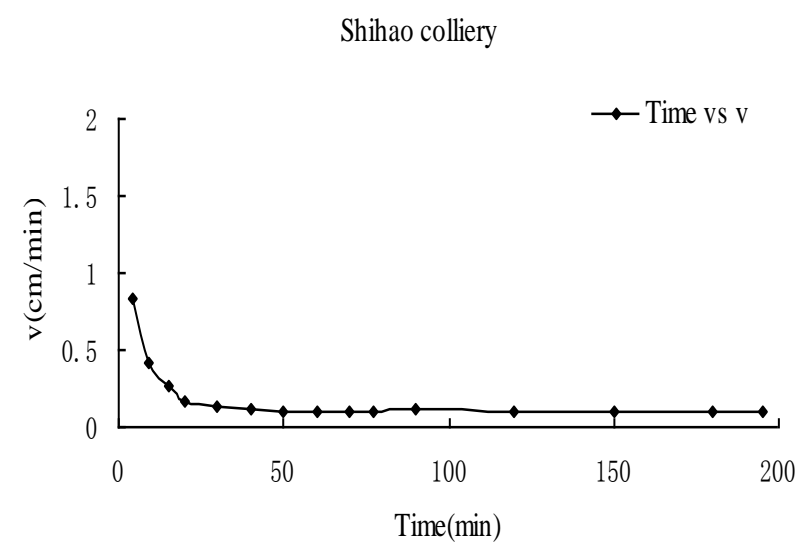

Figure 2. Infiltration curve of Shihao colliery.

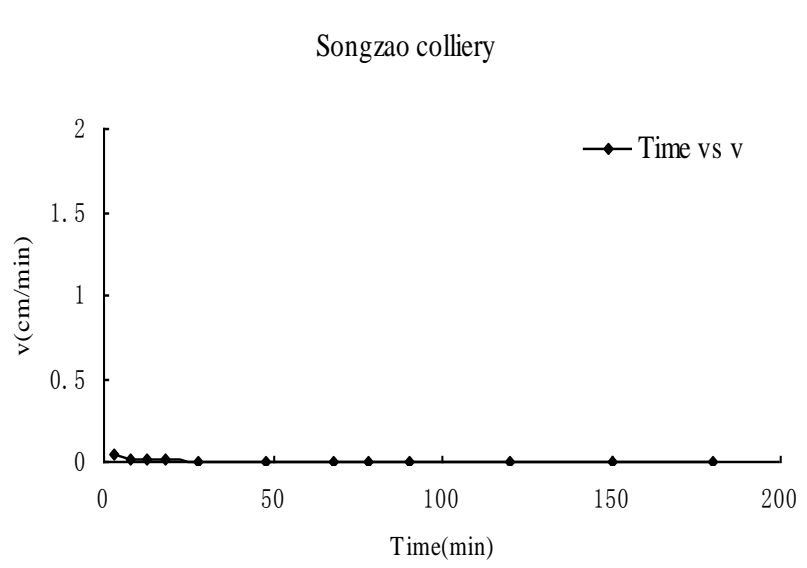

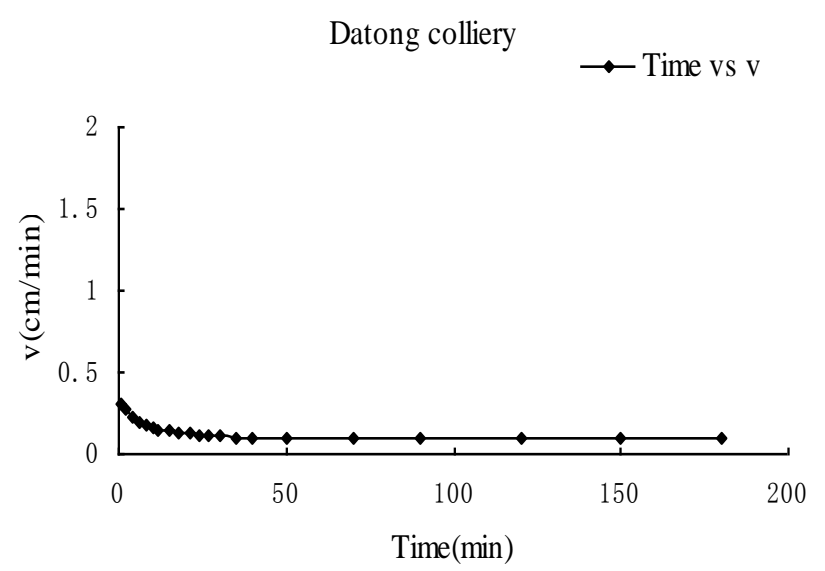

Figure 4. Infiltration curve of Datong colliery.



Figure 5. Infiltration curve of Fengchun colliery.

Yuyang colliery

$\rightarrow$ Time vs v

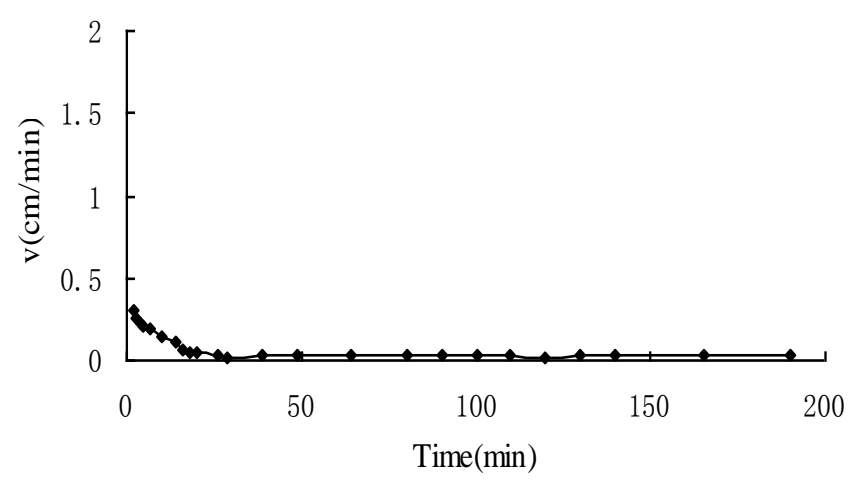

Figure 6. Infiltration curve of Yuyang colliery.

Figure 3. Infiltration curve of Songzao colliery. 
Tonghua colliery

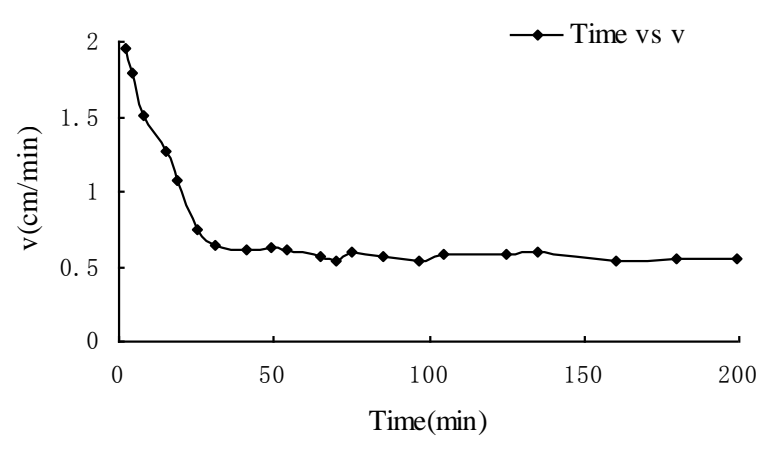

Figure 7. Infiltration curve of Tonghua colliery.

From above 6 figures, for Shihao colliery, the initial infiltration rate is $0.83 \mathrm{~cm} / \mathrm{min}$, stable rate arrived after 30 minutes, and the stable infiltration rate is $0.10 \mathrm{~cm} / \mathrm{min}$;

The initial infiltration rate is $0.05 \mathrm{~cm} / \mathrm{min}$, after 10 minutes, the stable infiltration rate is coming, and its value is $0.003 \mathrm{~cm} / \mathrm{min}$ in Songzao colliery;

The initial infiltration rate is $0.3 \mathrm{~cm} / \mathrm{min}$, the stable infiltration rate is $0.10 \mathrm{~cm} / \mathrm{min}$ after 35 minutes in Datong colliery;

The initial infiltration rate is $0.97 \mathrm{~cm} / \mathrm{min}$, reaching stable after 90 minutes, the stable infiltration rate is 0.38 $\mathrm{cm} / \mathrm{min}$ in Fengchun colliery;

The initial infiltration rate is $0.3 \mathrm{~cm} / \mathrm{min}$, the stable infiltration rate is $0.03 \mathrm{~cm} / \mathrm{min}$ after 25 minutes in Yunyang colliery;

And in Tonghua colliery, the initial infiltration rate is $1.96 \mathrm{~cm} / \mathrm{min}$, after 100 minutes, the stable infiltration rate is $0.55 \mathrm{~cm} / \mathrm{min}$.

\section{CONCLUSIONS AND DISCUSSION}

The experiment results showed that among six collieries Songzao colliery has the minimum permeability coefficient, while Tonghua colliery has the maximum permeability coefficient. Shihao colliery and Datong colliery have the same permeability coefficient.

Soil textures of Songzao colliery mainly are clay and silt, while Tonghua colliery mianly are silt and sand. The soil texture of both Shihao colliery and Datong colliery are silt and sand. Corresponding the permeability coefficient of sand is more than that of silt, and the silt is greater than the clay.
The size of vertical permeability coefficient decides the land water retention ability, controlling the infiltration water yield of rock stratum in infection zones in coal mining, determining the water consumption during the paddy cultivation period. In the case of insufficient of water supply, the water retention ability of soil determines it's easy or not of paddy field reclamation.

Soil infiltration curve is influenced by the soil texture (sand, silt and clay) and the soil moisture content. If the soil texture is same, the steady infiltration rate is approximately same. If the soil moisture content is adequate, the initial permeability curve of soil is steep, oppositely, if the soil moisture content is absent, the initial permeability curve of soil is flat.

\section{ACKNOWLEDGMENT}

The research was financially supported by the "Guangjiong" Research Fund of College of Resources and Environment, Southwest University (20150204), and Southwest University Doctoral Research Fund (No.SWU112059), and the supports were gratefully acknowledged.

\section{REFERENCES}

[1] Appels W M, Bogaart P W. Influence of spatial variations of microtopography and infiltration on surface runoff and field scale hydrological connectivity[J]. Advances in Water Resources, 2011, 34(2):303-313.

[2] Chen Zhantu. Priority appraisement of land regulation on subsidence area in five state-owned coal mining region,Chongqing[D]. Chongqing: Southwest University, 2010.

[3] Hu Chenglin. The Appliance Research of Integrated Geophysical Techniques on Colliery Gob[D]. Chengdu: Chengdu University of Technology, 2011.

[4] Li Jianzhu. Runoff generation model based on macropore infiltration and its application[D]. Tianjin: Tianjin University,2008.

[5] Li Meng. Analysis of Land Reclamation and Ecological Capacity in coal mining areas-A Case Study in Fenxi Mining Area[D]. Beijing: China University of Geosciences, 2012.

[6] Li Yuntao, Zhao Jingbo. Soil moisture content under artificial forests in Lantian and Chang'an regions[J]. Arid land geography, 2005, 28(4): 511-515.

[7] Ye Yuntao, Wu Jingwei, Wang Xingkui. Numerical simulation of double-ring measuration on hydraulic conductivity[J]. Journal of irrigation and drainage, 2007, 26(3):14-18.

[8] Zhang Lili. A certain mining area of Chongqing the inclined coal seam mined causes surface movement defor-mation mechanism and geological environmental problems[D]. Ningxia: Ningxia University, 2014. 